\section{(C) OPEN ACCESS}

\title{
The efficacy of hyperbaric oxygen therapy in the treatment of central retinal artery occlusion
}

\author{
Andreia Soares, Nuno L Gomes, Luís Mendonça, Carla Ferreira
}

Hospital de Braga, Braga, Portugal

\section{Correspondence to} Dr Andreia Soares, andreiafilipa.brsoares@gmail. com

Accepted 4 May 2017
CrossMark

To cite: Soares A, Gomes NL Mendonça L, et al. BMJ Case Rep Published Online First: [please include Day Month Year]. doi:10.1136/bcr-2017 220113

\begin{abstract}
SUMMARY
Central retinal artery occlusion (CRAO) is an ophthalmological emergency. Various treatment modalities have been tried, but none have shown to alter natural history of the disease. Hyperoxia can restore retinal oxygenation, and favourable results were obtained with hyperbaric oxygen therapy (HBOT). We report two patients with sudden visual loss due to CRAO treated with HBOT. Case 1: a 61-year-old female, presented with CRAO in her left eye(OS). She was submitted to eight sessions of HBOT(2.4atmosphere absolute (ATA)). BCVA(Best corrected visual acuity) improved from counting fingers (CF) to 1.0 and fluorescein angiography (FA) showed a normalisation. Vascular study showed a value of $8.8 \%$ for $\mathrm{HbA} 1 \mathrm{C}$ and ventricular extrasystoles. Case 2: a 69-year-old male presented with CRAO in his OS. Nine sessions of HBOT(2.4 ATA) were performed. Best corrected visual acuity (BCVA) improved from CF to 0.8 and the FA was normalised. Vascular study revealed an atheromatous carotid disease, and cardiac pathology. HBOT seems to be beneficial on the recovery of vision following CRAO.
\end{abstract}

\section{BACKGROUND}

Central retinal artery occlusion (CRAO) is an ophthalmological emergency and it is analogous to an acute stroke of the eye. The incidence is 1 in 100000 people. ${ }^{1}$ It is characterised by a sudden, unilateral and painless loss of vision. Embolism is the most common cause of CRAO, the major source of which being carotid artery disease.

The natural history of CRAO is the reperfusion of the artery over a few days. Meaningful improvement (15 ETDRS (Early Treatment Diabetic Retinopathy Study) letters or three lines in Snellen chart) occurs only in $10 \%$ of the patients with spontaneous reperfusion.

The prognosis is dependent on the particular vessel occluded, the location and degree of occlusion, the presence or absence of cilioretinal arteries, the time interval until therapy and presence of alternate sources of oxygen to ocular tissues. ${ }^{1}$

Traditional therapeutic regimens, including ocular massage, anterior chamber paracentesis, intraocular pressure-lowering medications, vasodilators and oral diuretics, have shown to be unsuccessful in the great majority of cases. Trombolytic agents and surgical embolectomy are associated with high haemorrhagic risk. ${ }^{1-3}$

Hyperbaric oxygen therapy (HBOT) has been associated with visual improvement in retrospective studies. ${ }^{2}$ HBOT can maintain oxygenation of the retina through the choroidal blood supply, decrease oedema and preserve compromised tissue adjacent to ischaemic area. ${ }^{24}$

We present two patients with CRAO who were submitted to HBOT. It is important to recognise that this treatment could be a good option if it is started earlier.

\section{CASE PRESENTATION}

Case 1: a 61-year-old woman patient presented to the emergency room with sudden loss of vision in the left eye (OS), which started 4 hours before the admission. Her past medical history included hypertension and type 2 diabetes mellitus. Her BCVA(Best corrected visual acuity) was CF OS and 1.0 OD(right eye), on a decimal scale. A relative afferent pupillary defect (RAPD) was present OS. Biomicroscopy of both eyes was normal. Intraocular pressure was normal in both eyes. Dilated fundus examination of the left eye showed an area of retinal whitening with redness in the foveal area. The right eye was normal. Spectral Domain Optical coherence tomography (SD-OCT) revealed increase in thickness and reflectivity of the inner retinal layers, consistent with intracellular oedema (figure 1A). Fluorescein angiography (FA) showed a delay on the filling phase of the central retinal artery (figure 2).

Case 2: a 69-year-old Caucasian man presented to the emergency room with sudden loss of vision in the left eye, started 2.5 hours before admission. Past medical history was significant for arterial hypertension and type 2 diabetes mellitus. BCVA was CF with positive RAPD OD and 1.0 OD. The anterior segment examination, intraocular pressure and fundus examination were normal in both eyes. FA of the left eye demonstrated delayed filling of the central retinal artery. OCT showed increase in thickness and reflectivity of the inner retinal layers, consistent with intracellular oedema.

\section{TREATMENT}

Case 1: the patient was referred to the Hyperbaric Medical Unit of Hospital Pedro Hispano, and was submitted to the first session of hyperbaric treatment at 2.4 ATA (atmosphere absolute) oxygen $(100 \%)$, during $90 \mathrm{~min}$, in a gas chamber. The first session was done 6 hours after the onset of symptoms. She was submitted to two additional daily sessions of $90 \mathrm{~min}$, on each one of the next 3 days, and one additional session on the fifth day. 

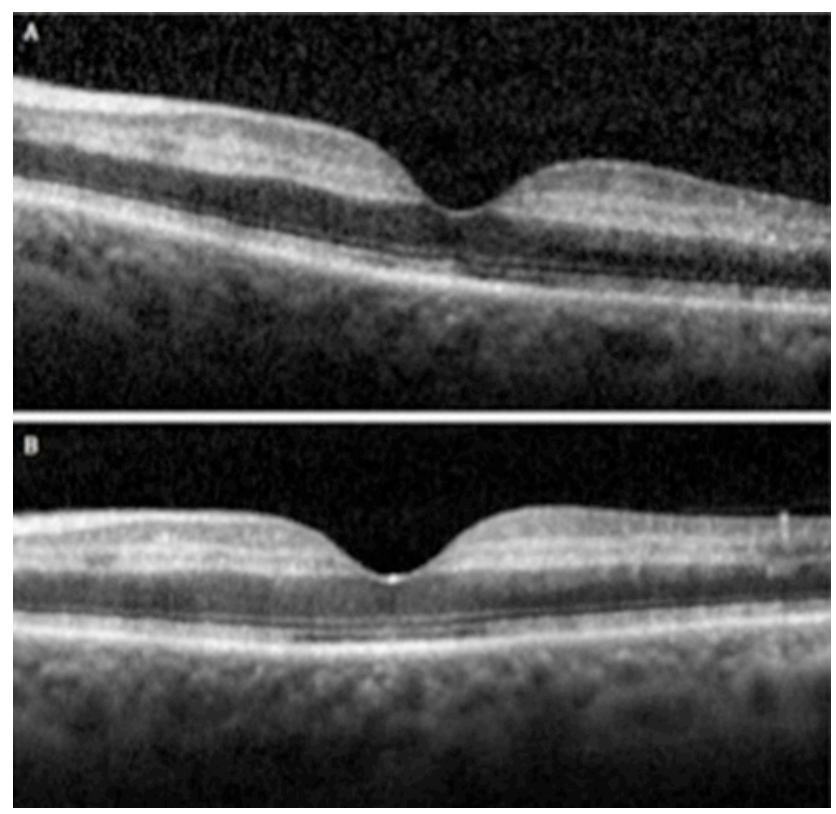

Figure 1 The first Spectral Domain Optical Coherence Tomography (SD-OCT) (A) revealed an increase in thickness and reflectivity of the inner retinal layers. The outer retinal layers are normal. The SD-OCT (B) performed 9 days after the diagnosis showed a normalisation of the inner retinal thickness.

Case 2: ocular massage was performed and topical antihypertensive medication was prescribed. Immediate referral to the HBO centre was undertaken. The first HBOT session was preformed 4 hours after the onset of the symptoms, in a gas chamber of the Hyperbaric Medical Unit of Hospital Pedro Hispano, at 2.4 ATA oxygen (100\%). Two additional daily sessions $(90 \mathrm{~min}$ ) were prescribed in the next 2 days, followed by only one daily session for the next 5 days.

\section{OUTCOME AND FOLLOW-UP}

Case 1: patient was checked for any other disease which could cause vascular occlusion, and we found a value of $8.8 \%$ for $\mathrm{HbA} 1 \mathrm{c}$ in laboratory tests, and the presence of ventricular extrasystoles on Holter (figure 3).

Three days after starting HBOT, BCVA OS improved to 1.0. Seven weeks after the initial visit, FA was repeated and showed normal fluorescein filling of the central retinal artery (figure 4). OCT was done in each one of the 3 days after the diagnosis, and was repeated after the 9 th and 37 th days (figure $1 \mathrm{~B}$ ). The

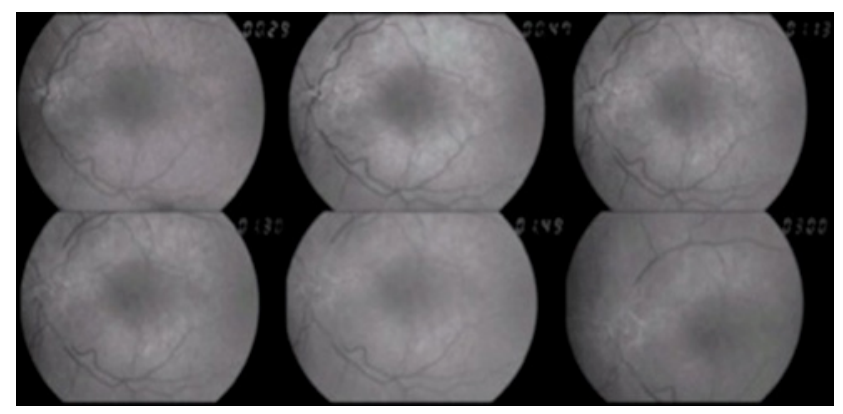

Figure 2 The first fluorescein angiography showed a non-perfusion (delay for more than $3 \mathrm{~min}$ ) of the central retinal artery, with near normal choroidal perfusion.

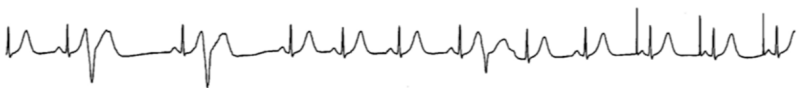

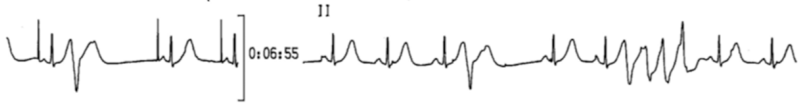

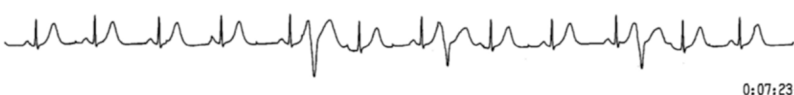

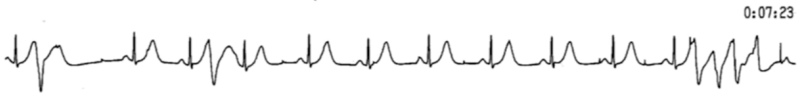

Figure 3 Twenty-hour Holter showed ventricular extrasystoles with ultrashort coupling interval $(260 \mathrm{~ms})$ and a non-sustained polymorphic ventricular tachycardia initiated by extrasystoles with short coupling interval.

thickness of the inner retina started to reduce on the third day after the diagnosis, and stabilised since the ninth day.

Case 2: patient was checked for any other disease which could cause vascular occlusion, laboratory examination showed hyperglycaemia and hyperkalaemia. The carotid echo-Doppler demonstrated atheromatous carotid disease, without significant dynamic repercussion, and echochardiogram found an enlargement of left auricle and hypertrophy of left ventricle, with mild aortic insufficiency.

Thirteen days after the initiation of therapy, the visual acuity of the left eye improved to 0.8 .

Ten days after the initial visit, control FA showed improvement in fluorescein filling of the central retinal artery (time arm-retina, $23 \mathrm{~s})$. OCT was done in each one of the 3 days after the symptoms, 1 and 2 months after. The thickness of inner retina started to reduce in the 10 th day and stabilised on the 14 th day.

\section{DISCUSSION}

HBOT is a treatment modality that can be used in many ocular pathologies. With hyperbaric oxygenation, oxygen can reach both inner and outer retinal layers retina by the choroid. An early administration of HBOT is extremely necessary to prevent irreversible damage to the retina. ${ }^{1-4}$

The administration of supplemental oxygen in the treatment of CRAO must be continued until flow through the retinal artery has resumed to a level sufficient to maintain inner retinal viability under normoxic conditions. ${ }^{1}$ Ideally, the shorter the time delay until treatment, the better the likelihood of recovering ischaemic retina that is threatened but viable. ${ }^{1}$

In the clinical setting of CRAO, however, some residual retinal blood flow has been detected by angiography. This may help explain the variability in visual outcome with different time delays until treatment.

Literature suggests that HBOT can also reduce macular oedema. ${ }^{5}$ The thickness of the inner retinal layers of our patients showed a progressive reduction, comparing with their fellow eyes, consistent with the reduction of the oedema.

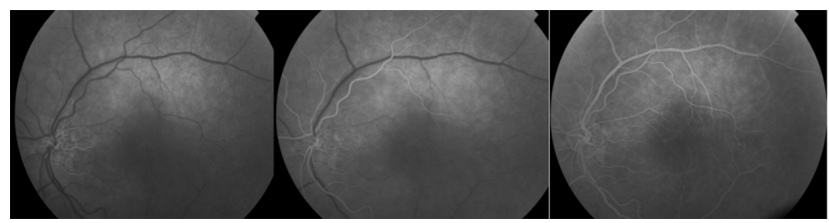

Figure 4 The second fluorescein angiography (after 7 weeks) revealed a normal fluorescein filling of the central retinal artery arterioles and capillaries, started at $18 \mathrm{~s}$. There is no retinal or macular ischaemia. 
Based on American Heart Association classification of evidence, treatment of CRAO with hyperbaric oxygen treatment is level IIb. There is fair to good evidence to support its use. It is acceptable and safe, but lacks confirmation by level I studies. There are no alternative therapies with similar outcomes. ${ }^{1}$

Many studies have reported that HBOT is useful in the treatment of CRAO, ${ }^{5-12}$ but that are different opinions about the period of time when HBOT can be useful. Butler et al ${ }^{11}$ reported that the best evidence is a delay of $<12$ hours. Hertzog et al ${ }^{12}$ and Beiran et $a l^{8}$ described that HBOT is most useful when started within 8 hours of onset visual loss.

The Undersea and Hyperbaric Medical Society advises that HBOT should be started in the first 24 hours after the onset of the symptoms, and it is reported that results are better if it is done in the first 12 hours. ${ }^{13}$

Some authors describe that there are four important key factors to determine the HBOT success: time at HBOT is started, degree of vessel occlusion, the type of vessel that is occluded and the presence of an adequate $\mathrm{PaO}_{2}$ of oxygen. The aetiology of the occlusion is also related as an important factor. ${ }^{14614}$

The major barrier to effective treatment for CRAO is the fact that people are rarely seen acutely and there is no consensus for treatment or guideline-based therapy. ${ }^{4}$

Our patients responded to the HBOT treatment well. The improvement may be related to the early timing of the treatment of our patients (6 hours) and the absence of other ophthalmological problem or precipitating factor.

\section{Learning points}

- Hyperbaric oxygen therapy (HBOT) seems to be an option for the treatment of central retinal artery occlusion (CRAO) that can be easily administrated.

- HBOT produce an improvement in vision if it is done in the first 24 hours after the onset of the symptoms.

- Further studies with more patients are necessary to determine the value and safety of this therapy in the treatment of CRAO, as well as the exact time window to perform HBOT.

Contributors AS: contribution to the conception and design of the work, acquisition, analysis and interpretation of data; draft the work; final approval of the version published; agreement to be accountable for all aspects of the work in ensuring that questions related to the accuracy or integrity of any part of the work are appropriately investigated and resolved. NLG: contribution to the analysis and interpretation of data; critical revision for important intellectual content; final approval of the version published; agreement to be accountable for all aspects of the work in ensuring that questions related to the accuracy or integrity of any part of the work are appropriately investigated and resolved. LM: contribution to the analysis and interpretation of data; critical revision for important intellectual content; final approval of the version published; agreement to be accountable for all aspects of the work in ensuring that questions related to the accuracy or integrity of any part of the work are appropriately investigated and resolved. CF: contribution to the conception and design of the work, acquisition, analysis and interpretation of data; critical revision for important intellectual content; final approval of the version published; agreement to be accountable for all aspects of the work in ensuring that questions related to the accuracy or integrity of any part of the work are appropriately investigated and resolved.

Competing interests None declared.

Patient consent Obtained.

Provenance and peer review Not commissioned; externally peer reviewed.

Open Access This is an Open Access article distributed in accordance with the Creative Commons Attribution Non Commercial (CC BY-NC 4.0) license, which permits others to distribute, remix, adapt, build upon this work non-commercially, and license their derivative works on different terms, provided the original work is properly cited and the use is non-commercial. See: http://creativecommons.org/ licenses/by-nc/4.0/

(C) BMJ Publishing Group Ltd (unless otherwise stated in the text of the article) 2017. All rights reserved. No commercial use is permitted unless otherwise expressly granted.

\section{REFERENCES}

1 Murphy-Lavoie H, Butler F, Hagan C. The Hyperbaric Oxygen Therapy Committee Report. Central Retinal Artery Occlusion. Gesell LB, editor. Hyperbaric oxygen therapy indications. 12th edn. Durham, NC: Undersea and Hyperbaric Medical Society, 2008:57-66.

2 Cope A, Eggert J, O'Brien E. Retinal artery occlusion: visual outcome after treatment with hyperbaric oxygen. Diving Hyperb Med Journal 2011;41:135-9.

3 Varma DD, Cugati S, Lee AW, et al. A review of central retinal artery occlusion: clinical presentation and management. Eye 2013;27:688-97.

4 Murphy-Lavoie H, Butler F, Hagan C. Central retinal artery occlusion treated with oxygen: a literature review and treatment algorithm. Undersea Hyperb Med 2012;39:943-53.

5 Weiss JN. Hyperbaric oxygen treatment of nonacute central retinal artery occlusion. Undersea Hyperb Med 2009:36:401-5.

6 Oguz H, Sobaci G. The use of hyperbaric oxygen therapy in ophthalmology. Surv Ophthalmol 2008;53:112-20.

7 Akil H, Keskin S, Alp M. Hyperbaric oxygen therapy in an isolated cilioretinal artery occlusion: a Case Report. Adv Ophthalmol Vis Syst 2015;2:1-3.

8 Beiran I, Goldenberg I, Adir Y, et al. Early hyperbaric oxygen therapy for retinal artery occlusion. Eur J Ophthalmol 2011;11:345-50.

9 Weinberger AW, Siekmann UP, Wolf S, et al. [Treatment of acute central retinal artery occlusion (CRAO) by Hyperbaric Oxygenation therapy (HBO)--pilot study with 21 patients]. Klin Monbl Augenheilkd 2002;219:728-34.

10 Aisenbrey $\mathrm{S}$, Krott R, Heller R, et al. [Hyperbaric oxygen therapy in retinal artery occlusion]. Ophthalmologe 2000;97:461-7.

11 Butler FK, Hagan C, Murphy-Lavoie H. Hyperbaric oxygen therapy and the eye. Undersea Hyperb Med 2008;35:333-85.

12 Hertzog LM, Meyer GM, Carsson S, et al. Central retinal artery occlusion, treated with hyperbaric oxygen.J Hyperbaric Medicine 1992;7:3-42.

13 Menzel-Severing J, Siekmann U, Weinberger A, et al. Early hyperbaric oxygen treatment for nonarteritic central retinal artery obstruction. Am J Ophthalmol 2012;153:454-9.

14 Wright JK, Franklin B, Zant E. Clinical case report: treatment of a central retinal vein occlusion with hyperbaric oxygen. Undersea Hyperb Med 2007;34:315-9.

Copyright 2017 BMJ Publishing Group. All rights reserved. For permission to reuse any of this content visit http://group.bmj.com/group/rights-licensing/permissions.

BMJ Case Report Fellows may re-use this article for personal use and teaching without any further permission.

Become a Fellow of BMJ Case Reports today and you can:

- Submit as many cases as you like

- Enjoy fast sympathetic peer review and rapid publication of accepted articles

- Access all the published articles

- Re-use any of the published material for personal use and teaching without further permission

For information on Institutional Fellowships contact consortiasales@bmjgroup.com

Visit casereports.bmj.com for more articles like this and to become a Fellow 